\title{
O PASSADO E AS PERSPECTIVAS FUTURAS DA RELAÇÃO ENTRE DESIGN E SUSTENTABILIDADE
}

\author{
Claudio Luiz Mangini ${ }^{1}$ \\ Diane Belusso ${ }^{2}$
}

\begin{abstract}
Resumo: Este é um ensaio teórico apoiado em revisão de cunho histórico, sociológico e epistemológico, derivado de pesquisa de mestrado acadêmico, desenvolvida em programa de pós-graduação interdisciplinar em Sustentabilidade, cuja temática é a relação histórica entre o design e a sustentabilidade, e que extrai dela alguns dados e a complementa em alguns pontos, em especial quanto à relação do tema com a pós-modernidade. Objetivouse destacar pontos entre a modernidade, a pós-modernidade e a degradação ambiental e investigar o caráter da nova face do design voltado para sustentabilidade. Regata-se, ainda, um histórico resumido das relações entre as escolhas estéticas do design e a formação da sociedade moderna de consumo. Os resultados apontam as tendências dos pensadores do design, influenciados tanto pelas demandas da atividade industrial, como pelas discussões mundiais sobre a questão ambiental e discute as perspectivas contemporâneas dos profissionais de design.
\end{abstract}

Palavras-chave: Sociedade de consumo; Designer; História do design, Desenvolvimento sustentável.

\section{THE PAST AND FUTURE PERSPECTIVES OF THE RELATIONSHIP BETWEEN DESIGN AND SUSTAINABILITY}

\begin{abstract}
This essay is supported by a historical, sociological and epistemological review, and results from an academic master degree's research, developed in an interdisciplinary program in sustainability, whose theme is the historical relationship between design and sustainability, developed using some of its data and complementing it in some topics, in special about the relationship between the theme and the postmodernity. The aim of this paper is to highlight points between modernity, postmodernity and environmental degradation and also to investigate aspects of the new face of design witch is aimed at sustainability. There is also a resume of the relationship between design's aesthetic choices and the formation of modern consumer society. The results point to the trends of design thinkers, influenced both by the demands of industrial activity, as well as by global discussions on the environmental issue, and discusses the designer's contemporary perspectives.
\end{abstract}

Keywords: Consumer society; Designer; History of design; Sustainable development.

\section{Introdução}

Se por um lado, nestas primeiras décadas do século XXI o design é apresentado como detentor de ferramentas para a sustentabilidade, por outro, essa atividade é historicamente ligada à produção industrial, tida como uma das principais responsáveis pela degradação ambiental. Diante deste raciocínio, há o questionamento acerca de como a atividade do design, que até recentemente esteve apenas e majoritariamente alinhada a práticas historicamente voltadas para a degradação ambiental, pôde, contemporaneamente, alinhar-se ao desenvolvimento sustentável. Esta temática é relevante e também incipiente do ponto de vista acadêmico, e pretende trazer contribuições diretas para a compreensão das dinâmicas entre economia, cultura e ecologia, no contexto da modernidade industrial e pós-industrial. O desenvolvimento estético e pragmático do

\footnotetext{
${ }^{1}$ Mestre em Sustentabilidade pelo Programa de Pós-Graduação em Sustentabilidade (PSU) UEM/ IFPR, Desenhista Industrial, docente do IFPR. E-mail: claudio.mangini@ifpr.edu.br

${ }^{2}$ Doutora em Geografia, docente do IFPR, vinculada ao Programa de Pós-Graduação em Sustentabilidade (PSU), associado UEM/ IFPR. E-mail: diane.belusso@ifpr.edu.br
} 
design, durante a modernidade, se voltou para a promoção da sociedade de consumo de bens industrializados, de modo tal que a função e forma afetam diretamente as dimensões humanas da necessidade e do desejo, respectivamente por uma associação entre motivações econômicas objetivas e subjetivas, atreladas à produção e ao comércio de objetos responsáveis por configurar a identidade do sujeito moderno. Assim, a atividade de design contribuiu para a degradação ambiental, através de sua proximidade com a indústria, determinando em parte os processos produtivos degradantes, e também por meio de ideologias estéticas, que influenciaram o desejo e contribuíram para a formação da sociedade de consumo; acredita-se, ainda, que na atualidade o design começa a trabalhar preocupado com o meio ambiente, não só devido à consciência dos designers, mas por pressões sociais e para a própria sobrevivência da profissão. Mas será mesmo que o design rompeu seu papel histórico de aliado de uma indústria produtivista, para passar a ser o detentor de um protagonismo cultural voltado para uma sociedade mais sustentável?

Acerca da metodologia de trabalho aplicada, optou-se pela revisão bibliográfica e pela apresentação no formato de ensaio, uma vez que na literatura existente sobre o tema (incipiente, lacunar e voltada principalmente para as aplicações das ferramentas do design em prol da sustentabilidade) não foram encontrados dados suficientes para sustentar todas as observações expressas neste trabalho, sendo que muitas delas se apoiam apenas na argumentação. Assim, não foi possível seguir, para a reflexão pretendida, um grau mais elevado de objetividade teóricometodológica ou de adotar-se alguns dos princípios de meta-análise ou bibliométricos, embora se tenha trabalhado dentro de uma perspectiva dialética e epistemológica, embasada na literatura disponível. À medida que os objetivos da pesquisa foram sendo alcançados, optou-se por organizar o texto deste artigo para apresentar os resultados em quatro partes principais: Semânticas e contextualizações; Design moderno e consumo; Transformação cultural e O Futuro do Design.

\section{Semânticas e Contextualização}

Já faz algum tempo que os objetos comuns do dia a dia assumiram um papel cultural. Os objetos extrapolaram o mero uso e passaram a assumir outras funções, como a de status social, de posicionamento cultural, de comunicação, de atitude política ou mesmo de rebeldia. A transformação destes produtos de uso para expressões da cultura material deve-se, entre outros fatores, à sua estética. Uma dada concepção estética passou a ser relacionada a um período histórico, a um movimento artístico e mesmo a uma concepção de mundo. As escolhas estéticas da qual o Design utilizou-se chega a um termo quase comum durante a primeira metade do século XX, onde as correntes modernistas do funcionalismo acabam por "definir" o que seria, 
em boa parte daquele século, entendido como Design. Esta mesma estética ajudou a definir os desejos da sociedade de consumo. Entretanto, essas escolhas estéticas e sociais, que definiram em boa parte o visual do século XX, foram colocadas em cheque a partir do momento em que a modernidade não foi capaz de dar respostas eficientes para melhorar o mundo. Isso promoveu uma série de transformações na sociedade, nas ciências e nas artes (aqui inseridas a Arquitetura e o Design) que passaram a ser tratadas, por alguns autores, como pós-modernas. O design foi transformado no final do século $\mathrm{XX}$, sendo colocado como um dos pilares da inovação necessária para transformar nossa sociedade de consumo para uma sociedade 'mais sustentável'. Mas, a história do design, sobretudo do design ligado ao desenvolvimento de produtos, está atrelada à sociedade industrial moderna, tornando-o corresponsável pelas transformações negativas no ambiente que nosso planeta vem enfrentando.

\section{Design}

O termo "design" é importado, um anglicismo relativamente recente na língua portuguesa $^{3}$, e que substitui termos como Desenho Industrial, Projeto, Comunicação Visual e Estilismo, entre outros, por se entendê-lo mais abrangente. Embora não seja assim tão novo, ainda gera confusões quanto ao seu uso, até mesmo com o termo derivado designer, que se aplica ao profissional de Design, e que aparece pela primeira vez no Oxford English Diccionary, já no século XVII (Cardoso, 2011, p.21-22). A própria definição do que seja Design, quer no Brasil, quer no mundo, também não é consensual. Com étimo primordial apontado como advindo do verbo latino "designare", passando pelo italiano "disegno", o termo gera, em língua portuguesa, os vocábulos "desenhar" e "designar" (NIEMEYER, 2007; CARA, 2010; CARDOSO, 2011). Seguindo-se a etimologia surgem definições que abrangem o desenho do produto e as intenções por ele designadas. Um cuidado que se deve ter com o termo é que, em língua inglesa, 'design' possui significado mais amplo do que quando usado dentro da Língua Portuguesa, de modo que as buscas por literatura em bases internacionais podem resultar em atividades em que se projete qualquer coisa, devendo-se evidenciar a que se está referindo ou buscando, como por exemplo: industrial design, graphic design, fashion design, forniture design, design for environment, etc. Com relação à atividade de Design em si, Niemeyer (2007, p. 24) aponta que as definições possuem uma tripla tipologia: de atividade artística, ligada à estética; de atividade inventiva, ligado à criação à tecnologia; e de coordenação e gestão, integrando as etapas de produção. As áreas tradicionais de atuação podem ser concentradas em três ramos

\footnotetext{
${ }^{3}$ Cara (2010, p. 80) aponta que o termo passa a ser utilizado no Brasil a partir da década de 1970.
} 
principais: Design de Produto (muitas vezes definido como sinônimo de Design Industrial), Design Gráfico e Design de Interiores, embora haja cada vez mais vertentes, como, por exemplo, o design de serviços e o design de interface, apenas para citar duas. Para Flusser (2007, p. 181182), mais importante que os aspectos históricos ou etimológicos do termo "design" é tentar entender como esta palavra "adquiriu o significado que se lhe atribui no discurso atual sobre cultura". Embora não haja consenso, e que ainda que se vá voltar ao assunto mais a frente, é importante eleger de antemão uma definição mínima, intrínseca ao pensamento dos autores deste ensaio, onde o design será entendido como uma atividade estratégica e intencional, aplicada para a solução de um problema, que resultará na idealização de um novo produto ou serviço, e que engloba os processos criativos, técnicos, formais e culturais envolvidos no projeto.

\section{Sustentabilidade}

Já a Sustentabilidade - que pode ser definida como a qualidade daquilo que é, ao mesmo tempo, ambientalmente correto, socialmente justo e economicamente viável, de acordo com as discussões fomentadas principalmente pela Organização das Nações Unidas (ONU), a partir das suas conferências sobre o meio ambiente - vem sendo estudada como um novo valor, por autores como Veiga (2010) e Baumgarten (2008). Associada a outras "grandes utopias", estaria lado a lado com a Liberdade, a Democracia e a Justiça Social (EHLERS, 2008. p.81). Em um primeiro momento a questão ambiental se apresentou como urgente e isso dividiu os ambientalistas entre aqueles que foram considerados como radicais, para os quais a preservação estava acima de tudo, e aqueles que passaram a pensar em uma forma de se desenvolver a sociedade e a economia sem degradar tanto a natureza. O poder político global, representado pela ONU, passou a apoiar a segunda vertente, provavelmente por esta ser mais ponderada diante das consequências históricas negativas que são atribuídas ao capitalismo moderno, tanto em relação à degradação da natureza, quanto às mazelas por ele impostas à sociedade. O pensamento ligado a Sustentabilidade econômica, social e cultural, defendido nas convenções da ONU, não levaria a uma ruptura radical com o modo pelo qual a política econômica é feita, nem à total transformação da sociedade como conhecemos, mas faria com que o mundo passasse por uma transição menos traumática para uma sociedade mais sustentável, levando em conta a evolução tecnológica da humanidade e tratando a questão de modo racional. Isso direcionou a busca por soluções que levassem à criação de uma sociedade menos prejudicial ao meio ambiente. Para Veiga (2010, p.115), "todas as esferas do conhecimento devem trazer a natureza de volta. Não por arrependimento romântico, mas como consequência da renovação das humanidades baseada nos 
mais recentes avanços obtidos nas ciências naturais e na história”. Em um momento seguinte, um ambiente de ideias progressistas com relação à igualdade, ocorrido nas últimas décadas do século passado e nos primeiros anos deste século XXI trazem certo otimismo nas perspectivas quanto aos avanços da sociedade. Binztok (2002, p.330) enaltece as conquistas em prol do meio ambiente e da sociedade: "Enfim, assistimos a uma grande mobilização social em escala planetária, reivindicando de forma vigorosa a ampliação dos direitos civis, em direção a uma plenitude democrática, como comprova o sucesso alcançado pelos fóruns mundiais alternativos". Mas, passadas quase duas décadas e desta afirmação, percebemos que a trajetória de evolução não está sendo tão linear quanto o vislumbre do referido autor: há recuos principalmente naquelas economias que têm mais impacto presente ou futuro sobre o ambiente, e que insistem em desequilibrar o tripé economia-ambiente-sociedade para apoiar-se apenas na economia. Além disso, a própria democracia vem sendo veladamente contestada por aqueles que tradicionalmente exerceram o poder e que, de certo modo, se sentem ameaçados pelo aumento das vozes que outrora compunham os setores mais silenciosos das sociedades, ao mesmo passo em que não enxergam nestas vozes a capacidade técnica para gerir a melhoria das próprias vidas, dentro de uma concepção meritocrática histórica que muitos detêm. E isto atinge também a consciência acerca da degradação ambiental.

\section{Modernidade e Pós-Modernidade}

Costuma-se chamar de pós-modernas, as mudanças culturais, artísticas e científicas ocorridas a partir da segunda metade do século XX. Como exemplos destas mudanças na cultura, arte e ciência, temos o movimento hippie, a pop-art e a invenção do chip (SANTOS, J.F. 2012). Ao tratar desta conceituação, em seu trabalho acerca da pós-modernidade, Oliveira (2011), ao analisar as teorias de Marcuse e Jameson, constata que "Qualquer tentativa de compreensão ou conceituação do pós-modernismo será, sempre e em primeiro lugar, um julgamento sobre a cultura e, mais ou menos explicitamente, sobre as sociedades capitalistas contemporâneas". Ressalta-se aqui que há quem negue a pós-modernidade. E há, ainda, autores que consideram que o pós-modernismo no design, embora até tenha existido, já acabou. Por exemplo, Souza (2008, p. 11) argumenta que:

O pós-modernismo no design durou menos do que se propunha e menos ainda do que se imaginava. No fim da década de 1980, Andrea Branzi, um de seus porta-vozes, afirmou que, diante do fim da história, uma atitude de vanguarda não poderia ser proposta para durar mais de dez anos. Houve nesta afirmação uma confusão conceitual. Foi uma apropriação da ideia de vanguarda, criação do ideário moderno [...]. Antes do prazo previsto por Branzi, as propostas pós- 
modernas já estavam em desuso intelectual, consumidas pela internet e pela mídia dos canais de TV a cabo, que precisam criar e descartar tudo o tempo todo, ainda que isso signifique apenas aparência. A vanguarda com data marcada não foi a superação do moderno, mas seu epitáfio.

Para efeitos deste trabalho, toma-se o partido da existência e da perseverança de uma pósmodernidade, e se considera a Atualidade como a luta da pós-modernidade contra a modernidade. Um dos principais impactos sobre o design na Atualidade é o da terceira Revolução Industrial, onde a mecânica é substituída pela eletrônica. Flusser (2007) destaca mudanças criadas pela interação "homem-ferramenta". Para o autor, a Primeira Revolução Industrial expulsou o homem da natureza, a Segunda o expulsou da sua cultura e a Terceira ainda não possui final passível de vislumbre realista. Porém, "quanto mais complexas se tornam as ferramentas, mais abstratas são suas funções" (FLUSSER, 2007, p.41). A nossa produção passa a estar "na nuvem", acessível de qualquer lugar, cada vez mais dependente de aparelhos eletrônicos, expulsando agora o homem do seu espaço de trabalho para um mundo no qual qualquer espaço se torna o seu espaço de trabalho, invadindo sua vida e sua casa depois do apito do final do expediente. Durante a Modernidade, tentou-se levar à frente soluções supostamente universais, teoricamente embasadas na racionalidade. Mas esse projeto 'modernista', nascido ainda durante o Iluminismo, relegou a religiosidade ao segundo plano, o que fez com que parte da humanidade se sentisse perdida, pois os seu(s) deus(es), que ditaram sua moral por séculos, são em parte destituídos pelo discurso lógico-racional. O combate ideológico acerca do que seria o 'melhor para humanidade' resultou, entre outras coisas, em duas grandes guerras mundiais, o que colocou em xeque a eficiência do racionalismo no que concerne à paz e ao bem-estar social universal. As evoluções científicas, como a darwiniana, acabaram por servir, através do 'darwinismo social', como 'justificativa' para o genocídio. Além de que os atores centrais da modernidade possuíam uma visão suspeita acerca de valores, que enalteciam o belicismo e a violência e que criminalizavam comportamentos naturais, porém menos convencionais da sexualidade humana, tais como a homossexualidade ou mesmo a exposição da nudez, apenas para citar dois pontos. Esses questionamentos acerca do pensamento moderno impulsionaram o caminho para o que se convencionou chamar de pós-modernidade. Depois disso, os caminhos que o mundo tomou vieram a transformar novamente a sociedade, provocando mudanças difíceis de serem ignoradas. Além das transformações na arte, cultura e ciência, houve também transformações importantes na própria sociedade de consumo. Sobre o assunto, Harvey (2008, p. 258), que dedica um bom número de textos à pós-modernidade, aponta que: 
Dentre os muitos desenvolvimentos da arena do consumo, dois têm particular importância. A mobilização da moda em mercados de massa (em oposição a mercados de elite) forneceu um meio de acelerar o ritmo do consumo não somente em termos de roupas, mas também numa ampla gama de estilos de vida e recreação (hábitos de lazer e de esporte, estilos de música pop, videocassetes e jogos infantis etc.) Uma segunda vertente foi a passagem do consumo de bens para o consumo de serviços - não apenas serviços pessoais, comerciais, educacionais e de saúde, como também de diversão, espetáculos, eventos e distrações. [...] Como há limites para a acumulação e para o giro de bens físicos [...] faz sentido que os capitalistas se voltem para o fornecimento de serviços bastante efêmeros em termos de consumo. Essa busca pode estar na raiz da rápida penetração capitalista [...] em muitos setores da produção cultural a partir da metade dos anos 60.

Apesar do lapso temporal entre o texto de Harvey e o trabalho ora apresentado, a PósModernidade é responsável por algumas das 'soluções' que permitem a sobrevivência do capitalismo (e do design a ele alinhado) dentro da era da Sustentabilidade. Como vimos, uma das estratégias é a substituição de produtos por serviços, contemplada pelo autor. Por outro lado, a preservação do consumo como força motriz da economia é uma das características que formou o mundo Moderno. Pode-se assim dizer que a melhor forma de se compreender a PósModernidade seja confrontá-la com a Modernidade. Sobre o antagonismo moderno versus pósmoderno Terry Eagleton (1995, p.53) escreve que:

É como se o pós-modernismo representasse a cínica e tardia vingança da cultura burguesa contra seus antagonistas revolucionários, cujo desejo utópico de uma fusão entre arte e práxis social é tomado, torcido e zombeteiramente voltado contra eles próprios como realidade distópica. O pós-modernismo, nessa perspectiva, arremeda a resolução formal de arte e vida social tentada pela vanguarda, ao mesmo tempo que impiedosamente a esvazia de seu conteúdo político; as leituras poéticas de Maiakovski no espaço das fábricas se transformam nos sapatos e nas latas de sopa de Warhol.

E mais a frente que:

O pós-modernismo empresta algo do modernismo e da vanguarda e, em certo sentido, coloca um contra a outra. Do modernismo propriamente dito, o pósmodernismo herda o eu fragmentário e esquizóide, mas extirpa toda a distância crítica dele, contrapondo a isso uma impassível apresentação de experiências "bizarras" que se assemelha a certos gestos de vanguarda. Da vanguarda, o pósmodernismo toma a dissolução da arte na vida social, a repulsa à tradição, uma oposição à "alta" cultura enquanto tal, mas mistura isso com os impulsos apolíticos do modernismo (EAGLETON, 1995, p.68).

Isso posto, além do esvaziamento político notado pelos autores, percebe-se que o antagonismo entre as temporalidades parece ser a melhor forma para conceituar a pósmodernidade. 
Com relação ao termo "moderno" e seus termos derivados: "modernismo", "modernidade" e "modernização", é comum que existam confusões. A principal delas é causada pela clássica divisão da História (da Europa), ao considerar o final da Idade Moderna na Revolução Francesa (marcada pela Queda da Bastilha, em 1789), a partir da qual começaria a Idade Contemporânea. Para a Arte, a Arquitetura e o Design, o modernismo está ligado ao final do Século XIX e, principalmente, à primeira metade do Século XX, derivando, justamente do pensamento Iluminista, protagonista da Revolução Francesa. Dentro da Estética, a arte fica realmente conhecida por Arte Moderna nos movimentos artísticos posteriores ao Impressionismo (de Monet) e ao Pós-Impressionismo (de Cézanne e Van Gogh). Assim a Modernidade desenvolve-se, de acordo com aquela divisão da História, dentro da Idade Contemporânea.

Em meados dos anos 1960, Norbert Lynton escreveu que as primeiras décadas do século XX "testemunharam uma série extraordinariamente rápida de movimentos revolucionários na arte e na arquitetura” (LYNTON, 1978, p.79). O Expressionismo, o Abstracionismo, o Futurismo, o Cubismo e o Neoplasticismo - movimentos ocorridos na primeira metade do século XX - são considerados pelos historiadores e críticos de arte, como Arte Moderna. Para a cultura e sociedade, em geral, a primeira metade do século XX é a temporalidade conhecida por Modernidade. Para a Arquitetura e o Design, o modernismo é não somente o período de profusão das correntes projetivas com caráter prioritariamente funcionalista, sintético e racional, mas também um nome genérico para os estilos que estão inseridos nestas correntes, que são chamados de modernistas. É nesse período, iniciado a partir da virada para o século XX, que o mundo se "moderniza".

\section{Design e Sustentabilidade, Modernidade e Pós-Modernidade}

É difícil alinhar a posição do Design voltado para o Desenvolvimento Sustentável em nossa contemporaneidade: o atual conceito de Sustentabilidade contém, implicitamente, uma vitória racional sobre o absurdo de se destruir o ambiente e, por esse prisma, estaria diretamente ligada ao pensamento moderno; por outro lado, pode-se também se assumir que o novo Design voltado para a Sustentabilidade é um fenômeno pós-moderno, pois está ligado ao ativismo ambiental nascido durante a Contracultura, estando relacionado diretamente às criticas sociais tecidas pelos movimentos pós-modernos. Para se evitar a colocação da relação DesignSustentabilidade dentro das premissas ou da modernidade ou da pós-modernidade, vamos apenas chamar nosso contexto histórico de Atualidade. 
Entretanto, cabe uma rápida explicação sobre o que seria a Modernidade e a PósModernidade, pois as temporalidades teóricas embasam várias das reflexões que este ensaio suscita. No final do século XX culmina a crítica à degradação ambiental dentro do Design, não apenas preocupada quanto ao destino da humanidade, face ao seu impacto causado no planeta, mas reagindo às novas pressões provocadas pela discussão acerca da degradação ambiental.

A partir dos anos 1990, e em particular a partir da Rio92, quando a definição de Desenvolvimento Sustentável se solidifica, estudiosos e propositores de metodologias do design se debruçam sobre o tema. Entre as obras que fazem parte de período, podemos destacar "Green Design: Design for the Environment", de MacKenzie (1991) "Prometheus of the Everyday - The Ecology of the Artificial and the Designer's Responsibility" de Manzini e Cullars (1992) e a tese "Ecodesign", de Emma Dewberry (1996). Novos autores da metodologia do projeto dentro do design, tais como Mike Baxter (1998), passam a incluir ferramentas de Sustentabilidade em suas obras. O design assim passou, ao menos na literatura, de aliado da degradação ambiental para ser fornecedor de soluções para o Desenvolvimento Sustentável, através de diversos níveis de intervenção, recorrendo a artifícios abordados em autores tais como Kazazian, (2009); Manzini e Vezzoli, (2005) e Baxter (2011), que podem ser resumidamente listados como: análise do ciclo de vida durante o desenvolvimento dos produtos; novos métodos de gestão de tempo; o gerenciamento da matéria-prima; passar do uso de produtos para a elaboração de serviços que tragam a mesma satisfação; fazer uso de conceitos tais como utilizar no lugar de possuir, gerenciar ou eliminar a obsolescência, alongar a vida do produto, alongar a vida do material utilizado no produto, fazer reaproveitamento, reuso, desvio de função; otimizar as etapas de produção; reduzir as embalagens, etc. A própria definição do que seja o Design vem sendo renovada para incorporar os atuais pilares da sustentabilidade. De acordo com a World Design Organization - WDO4, hoje o Design Industrial é definido como:

um processo estratégico para a solução de problemas, que impulsiona a inovação, constrói o sucesso do negócio e leva a uma melhor qualidade de vida por meio de produtos, sistemas, serviços e experiências inovadores. O design industrial preenche a lacuna entre o que é real e o que é possível. É uma profissão interdisciplinar, que aproveita a criatividade para resolver problemas e co-criar[sic] soluções, com a intenção de tornar melhor um produto, sistema, serviço, experiência ou negócio. Na sua essência, o Design Industrial oferece uma maneira mais otimista de olhar para o futuro, convertendo problemas em oportunidades. Ele conecta inovação, tecnologia, pesquisa, negócios e clientes, a fim de fornecer novos valores e vantagens competitivas nas esferas econômicas, sociais e ambientais (WDO, 2015)

\footnotetext{
${ }^{4}$ Definição atualizada pela $29^{\mathrm{a}}$ assembleia geral da WDO, Gwangju, 2015 - Coreia do Sul.

${ }^{5}$ Tradução nossa.
} 


\section{Design Moderno E Consumo}

A distribuição do homem pelo mundo muda a partir da primeira revolução industrial, que ocorre em meados do Século XVII, sendo que as migrações são intensificadas a partir da metade do Século XVIII, com a segunda Revolução Industrial. A origem desta revolução seria a GrãBretanha, através de descobertas científicas e avanços tecnológicos, que transformaram o carvão mineral em uma fonte "dinâmica de energia" (GIDDENS, 2009, p. 57). Fundamentando-se nos ricos textos de Hobsbawn (1979) acerca da revolução industrial, pode-se dizer, de forma simplista, que a manufatura se tornou aos poucos mecanizada ao passo que a indústria têxtil ganhou força, mudando as relações entre a cidade e o campo. Além de outros fatores, a dependência de matéria prima abundante para a produção industrial transformou também a produção agrícola. O crescimento populacional aumentou a demanda por alimento, que resultou na necessidade de expansão das fronteiras para a pecuária e para a agricultura. Os centros urbanos, cada vez maiores, influenciaram na produção e no descarte de resíduos e provocaram mudanças em microclimas. A população começou a deixar o campo e se estabelecer em cidades em torno das indústrias e as famílias passaram a dispender seu dia nas fábricas. O poder econômico aos poucos saiu das mãos da nobreza para as mãos dos Industriais. A formação de uma nova sociedade, mais urbana, levou ao aumento da industrialização de bens. E a necessidade de produção e de transporte de bens aumentou a necessidade de produção de energia, que levou à maior extração de combustíveis fósseis, como o carvão ( $1^{\mathrm{a}}$ Revolução Industrial) e o petróleo ( $2^{\mathrm{a}}$ Revolução Industrial), e também à extração de minérios e de outros recursos naturais para servirem de matérias-primas. Enfim, a complexidade da sociedade que se formava demandava cada vez mais de recursos provenientes da natureza e concentrava a população mundial nas cidades.

E é durante a Revolução Industrial que a atividade de Design Industrial se solidifica como hoje a compreendemos, ligada ao capitalismo industrial. O escocês Adam Smith, com o rigor científico da época, analisou e descreveu o sistema capitalista em 1776, em sua célebre Obra "A riqueza das Nações: uma investigação da sua Natureza e suas Causas”. Suas premissas, que traziam o princípio da divisão do trabalho (SMITH, 1996) só foram contestadas com argumentos relevantes em 1867, também com o relativo rigor científico possível, quando o filósofo e sociólogo alemão Karl Marx escreveu sua coleção de textos que ficaram conhecidos como "O Capital", lançando críticas ao modo de produção capitalista, apontando suas falhas, entre as quais estava a injustiça social (MARX, 1867). Entretanto, este antagonismo estava focado somente nas esferas social e econômica, pois a finitude dos recursos naturais ainda não 
estava em pauta entre os teóricos. A Revolução Francesa ocorreu entre os trabalhos de Adam Smith e Karl Marx e os eventos por ela desencadeados, que em um primeiro momento rebelaram-se contra o absolutismo monárquico, fizeram com que, em seguida, se evidenciasse a luta de classes entre os donos do capital e os trabalhadores, o que daria a tônica de uma série de discussões ideológicas que acompanhariam e moldariam a Modernidade.

\section{Design e Industrialização: Crítica e Alinhamento}

Seguindo a maioria dos historiadores do Design, faremos uma linha do tempo entre o movimento Arts and Crafts e a escola germânica Bauhaus, dividindo-se então entre as influências norte-americanas no pós-guerra e as influências germânicas da escola de Ulm (DORFLES, 1978; CARDOSO, 2011; NIEMEYER, 2007 e BÜRDEK, 2010), isso para tentar explicar as escolhas estéticas do Design que dominou o século XX.

Lembramos que esta "historiografia oficial" é em parte criticada por autores como Adrian Forty (2007) e por Pedro Luiz Pereira Souza (2008), pois, segundo eles, da maneira que tradicionalmente está posta, a História do Design parece resultar mais de feitos de pessoas extraordinárias que de outros fatores de ordem política, social e cultural. Entretanto, estes autores atêm-se aos mesmos momentos históricos, porém sendo mais críticos em relação às suas causas. Seguiremos em parte alinhados a esta crítica, e olharemos para esta historiografia, buscando também os fatores que ajudaram a estabelecer o nexo atual entre a sustentabilidade e o design.

Para se indicar o surgimento de novos movimentos estéticos, é necessário que se apontem quais os paradigmas estéticos anteriores quebrados. A arte na época da Revolução Industrial está dividida: por um lado está embasada no Romantismo e, consequentemente, em um naturalismo idílico e, por outro lado, ao Neoclassicismo, mais racional e ligado a uma estética mais geometrizada, porém também amparada pela natureza. Os limites fabris da incipiente indústria de produtos e a preocupação centralizada no como fabricar, certamente levaram, em um primeiro momento, a uma relegação da estética a um plano secundário. Essa quebra de paradigma, provocada em grande parte pela inépcia da indústria em replicar a arte de sua época, provoca uma crítica que ao mesmo tempo é uma retomada do passado e uma revolução.

Arts and Crafts. O movimento Arts and Crafts $^{6}$ é indicado por vários dos autores pesquisados como sendo o primeiro na história do design responsável por tecer críticas à sociedade industrial (DORFLES, 1978; CARDOSO, 2011; BÜRDEK, 2010 e DROSTE, 1995). Não era apenas um movimento estético e estilístico, mas estava alinhado ao romantismo tardio e

${ }^{6}$ A expressão significa Artes e Ofícios, mas, quando se refere ao movimento, este é mais conhecido em sua grafia original, em inglês. 
ao revivalismo medieval, e buscava, ideologicamente, por uma estética mais ligada à produção artesanal, fazendo um contraponto aos produtos industrializados, em parte por seus membros simplesmente considerá-los feios, e em parte por discordar categoricamente da sociedade que se formara a partir da industrialização. Forty $(2007$, p.63) ressalta que é "importante lembrar que o grau de mecanização nas indústrias em meados do século XIX era muito menor do que geralmente se supõe", e se baseava em grande parte na habilidade manual dos trabalhadores. Assim, o movimento normalmente ligado a valorização do trabalho do artesão, na verdade não era tanto o resgate do artesanato, mas se contrapunha ao modo de produção capitalista. Esse movimento influenciou fortemente a atividade do Design ocidental (THE WILLIAN, 2011-2018) e os dois movimentos de origem francesa que a ele se seguiram: o Art Nouveau e o Art Déco, ambos também considerados igualmente influentes no Design a partir de então, de acordo com os mesmos autores já citados no parágrafo anterior. O Arts and Crafts pode ser visto como atuante nos três pilares contemporâneos da sustentabilidade: os intelectuais da época criticavam a poluição gerada pelos primeiros cem anos da revolução industrial; buscava uma alternativa à sociedade industrial, pois seus membros não gostavam dos resultados sociais que a industrialização promovia; e propunha uma nova economia, baseada na produção artesanal, onde os produtos pudessem ser feitos por pessoas mais próximas aos usuários. Apesar das preocupações socialistas de seus membros, entre os quais estavam os artistas do movimento autodenominado irmandade pré-rafaelita ${ }^{7}$, os produtos acabaram por assumir um caráter elitizado, contrariando muitos dos princípios pregados por estes intelectuais.

Art Nouveau. Sob a influência deste pensamento, sobretudo devido ao fato de os produtos então oriundos da indústria não agradarem às elites, e também devido ao crescente comércio com o oriente e o contato com a arte japonesa, que carregava uma estética diferente daquela que a Europa conhecia até então, originou-se a formação de um design que abusava das formas orgânicas, como, por exemplo, vistas no estilo exibido pelas famosas luminárias e abajures projetados por Louis Comfort Tiffany. Este movimento recebeu o mesmo nome da loja que inicialmente comercializava produtos com estes conceitos: Art Nouveau. As variantes deste movimento na Europa, como a escola de Bruxelas, o Jugendstil na Alemanha e a escola de Glasgow, não negavam totalmente a industrialização, embora ainda valorizassem a produção

\footnotetext{
${ }^{7}$ Do inglês "Pre-Raphaelite Brotherhood". Grupo fundado em 1848 por Dante Gabriel Rossetti, William Holman Hunt e John Everett Millais, todos artistas britânicos que contestava a direção dada ao mundo após o Renascimento (daí vem a citação no nome ao pintor renascentista Rafael Sânzio), e pregava um revivalismo medieval, principalmente neo-gótico - nota dos autores.
} 
artesanal. O crítico de arte e historiador do Design, Gillo Dorfles (1978, p.134) nos ensina que, por muito tempo, a corrente conhecida como Art Nouveau foi vista como "uma corrente oposta à 'racionalista' e inimiga dela", mas que apesar de "distintas e contrárias, tiveram paralelamente a função de promover o emprego da máquina na criação". O uso dos novos materiais e técnicas, assim como as formas curvas, espalhavam-se pelos objetos de consumo, pelo design gráfico e pela Arquitetura. A estética adotada também fez forte presença nas artes plásticas, criando uma aproximação estética entre as belas artes e os produtos de consumo. O movimento espalha-se e atinge também as Américas. Dos atuais pilares da sustentabilidade podemos destacar que a preocupação ambiental, do ponto de vista ecológico, não estava na mente dos produtores e consumidores do Art Nouveau, entretanto o ambiente urbano transformou-se esteticamente, nas fachadas e no mobiliário urbano, como, por exemplo, nas entradas das estações do metrô de Paris. Com relação aos objetos de consumo, o movimento buscava principalmente destacar a posição social dos seus consumidores, pois se tratavam de produtos caros e de difícil fabricação, que demandavam mão de obra altamente capacitada; do ponto de vista econômico, os produtos do Art Nouveau movimentaram o mercado devido ao agrado do gosto da próspera sociedade da Bélle Époque. Gombrich (1997, p. 558) nos diz que “[...] se Morris estava certo em pensar que a máquina jamais poderia com sucesso emular o trabalho da mão humana, a solução estava obviamente em encontrar o quê a máquina poderia fazer, e ajustar os projetos de acordo com isso",

Art Déco e Styling. O Art Déco (uma abreviação francesa para 'arte decorativa') extrapola seu nome para além dos objetos de decoração e abraça em boa parte a industrialização. A sua estética buscava formas mais geometrizadas em relação ao Art Nouveau e os produtos adquiriam um visual futurista. Essa estética atingiu os objetos de consumo, os produtos industrializados, o Design Gráfico e a Arquitetura, tendo grande sucesso em especial na América do Norte na primeira metade do século XX, do qual são exemplos famosos arranha-céus em Nova Iorque, como por exemplo o edifício da Chrysler e o Empire State Building. Com uma geometria mais simples, os objetos criados sob esta estética eram passíveis de industrialização com a tecnologia da época, de modo que os produtos projetados puderam ser produzidos em larga escala. Cabe ressaltar que, nessa época, na América do Norte, após a crise da bolsa de Valores de 1929, surgiu o Styling (DORFLES, 1978), que acabou por virar sinônimo do Desenho Industrial norte-americano, com linhas que, em geral, possuem uma estética muito próxima à do Art Decó. Como exemplos deste movimento norte-americano podemos citar os objetos

\footnotetext{
${ }^{8}$ Tradução nossa.
} 
projetados por Raymond Loewy. Essa forma de fazer design acabou por ligar-se ao conceito mercadológico da obsolescência programada, de modo que novos projetos passaram a lançar um produto de mesma função, mas com um novo atrativo formal, tornando o modelo anterior obsoleto (DORFLES, 1978). Esse modelo econômico, aliado ao desenvolvimento industrial inaugurado por Ford, somado ainda ao modelo social formador de uma sociedade consumidora, ganhou robustez no mesmo passo que os Estados Unidos ganharam força durante a Segunda Guerra Mundial. Esse lançamento contínuo de novos produtos contribuía para a manutenção econômica e mantém os empregos dos consumidores (faz-se aqui um parêntese para constatar que a estratégia da obsolescência programada é extremamente atual), garantindo a estabilidade social, de tal forma que esse modo de vida estadunidense dos anos 1950 - que ficou conhecido como "american way of life" - passa a ser um paradigma perseguido pelas sociedades ocidentais. Evidentemente, levados em conta os atuais pilares da Sustentabilidade, o principal ponto a ser condenado no styling é o fato de que a obsolescência programada contribuiu em muito para a degradação ambiental, uma vez que os produtos obsoletos simplesmente passaram a ser descartados. Por outro lado, o movimento dava sustentação à sociedade, pois mantinha os empregos, trazia mais conforto à população norte-americana, a ponto de, o seu modo de vida, ser um exemplo para o mundo ocidental; além disso, a constante produção mantinha as fábricas em funcionamento, tornando a economia pujante, mas com altos custos ambientais e ecológicos que só seiam notados nas décadas seguintes.

Funcionalismo racional. Os princípios formais e conceituais do Arts and Crafts e do Art Nouveau foram unidos e desenvolvidos na Escócia, principalmente por Mackintosh e MacMurdo, conforme aponta Dorfles (1978, p.133) e posteriormente são levados às terras germânicas por Muthesius, que se envolve com os fundadores da "Werkbund", uma associação alemã de trabalhadores. Estes projetistas queriam aliar o potencial da indústria a uma concepção mais racional, a fim de gerar produtos que dessem, ao mesmo tempo, uma resposta à nova sociedade que se formava e que também fizessem uso das novas tecnologias existentes (DROSTE, 1995). Houve lá uma briga conceitual entre dois de seus principais atores, o belga Van de Velde, defensor da produção artesanal e o germânico Walter Gropius, defensor da produção industrial. Este último levou vantagem. A Primeira Guerra Mundial acabou por colocar a Bélgica e a Alemanha em lados opostos, de modo que Van de Velde teve de deixar as terras germânicas. Walter Gropius é apontado como o principal fundador da escola Bauhaus, reconhecida como o berço do funcionalismo e responsável pelas bases pedagógicas do Design nas escolas que a sucederam pelo mundo afora (CARDOSO, 2011 e BÜRDECK, 2010). Com um sistema que se 
embasava na arte para a criatividade, e na função do uso para a concepção de produtos, a escola deu as bases para a corrente funcionalista que imperou na primeira metade do século XX. A partir da Bauhaus, o Design passou a projetar para a indústria, à qual se aliou em definitivo. Ainda antes da Segunda Guerra Mundial, em 1933, a Bauhaus foi encerrada pelos nazistas (DROSTE, 1995) e expoentes da escola migraram para os Estados Unidos, como por exemplo o Arquiteto Mies Van der Rohe, responsável pela proliferação do célebre enunciado "menos é mais", introduzindo no território norte-americano uma nova estética, bem diferente daquela adotada pelo styling. Seus conceitos são adaptados e transformados por Mies Van der Rohe e pelo arquiteto francês Le Corbousier, revolucionando esteticamente também a Arquitetura, em um movimento que passou a ser conhecido por International Style. Após a segunda guerra, na Alemanha, a escola de Ulm, fundada em 1951 por Max Bill, um ex-aluno da Bauhaus, foi a responsável pelo desenvolvimento das premissas que se iniciaram no entre-guerras. Bill contrariava em parte o funcionalismo pregado pela Bauhaus, querendo dar maior ênfase a função formal do projeto. Niemeyer (2007, p 47), aponta que, em 1956, a direção da escola é assumida por Tomas Maldonado, que "desconfiava do romantismo idealista da maioria do pensamento préguerra", achando absurdo manter o modelo de ensino de quarenta anos atrás. Maldonado ajudou a redefinir o design de produto como parte do processo de produção e se opôs às premissas estéticas do styling norte-americano, buscando linhas limpas através de um pensamento racional, em oposição ao impacto emocional causado pelos apelos a um novo atrativo meramente ornamental.

Síntese do alinhamento histórico do design à industrialização. De maneira meramente cronológica e não dialética sintetizamos o que foi exposto neste tópico, para melhor compreensão daqueles que não estão familiarizados com a História do Design. A incipiente industrialização, devido a limitações tecnológicas, quebra com os paradigmas artísticos da época, elaborando produtos considerados por muitos de mau gosto. Isso se alia a uma insatisfação com as mazelas sociais provocadas pela industrialização. O movimento Arts and Crafts, basicamente por esses motivos, se opõe a industrialização tentando uma volta ao artesanato. Em seguida, o movimento Art Nouveau, que também não gosta das soluções da indústria, mas que não quer negá-las, incorpora aos projetos os novos materiais da engenharia. Enquanto isso, no EntreGuerras, na Alemanha, se desenvolve a corrente precursora do funcionalismo, dentro da Escola Bauhaus ligando o design a indústria, através de uma estética limpa e não-ornamentada, diversa da pregada pelo Romantismo e pelo Neoclassicismo. O Art Decó encontra uma estética que é um pouco mais geometrizada em relação ao Art Nouveau e por isso passível de industrialização. Seu 
alcance global chega aos Estados Unidos, evoluindo para o Styling, ligado à concepção de novos produtos para indústria e ao conceito mercadológico da obsolescência programada. Estas duas correntes, o Styling e o Funcionalismo, são fomentadas pela propaganda e colaboram para a formação da Sociedade de Consumo.

\section{Design no Brasil.}

O design chega ao Brasil depois da industrialização do País, e com a lógica dos membros mais ferrenhos da ideologia racional modernista, que passaram até a negar que se tratasse por 'design' projetos de produtos que tivessem algo de lúdico ou figurativo, ditando um modelo de objeto limpo e funcional.

Enquanto a América do Norte enfrentava a quebra da Bolsa de 1929, o Brasil monoculturista enfrentava uma crise de café provocada por fatores diversos, entre eles o excesso de estoques reguladores. Se, por um lado, o caráter de exportador agrícola do Brasil enfrentava dificuldades, as reservas do capital dos produtores rurais foram investidos em uma diversificação industrial, "sobretudo em São Paulo", com expansão de setores "como da metalurgia, da mecânica, do cimento, do papel” (NIEMEYER, 2007; p.52). Devido às Guerras, caiu a exportação de alimentos e houve aumento na demanda por produtos industrializados. Entretanto, o Brasil, que perdeu força como agroexportador, ainda estava muito longe de ser um país industrializado. Niemeyer (2007) aponta que, após o alinhamento de Getúlio Vargas com os Estados Unidos durante a Segunda Guerra, a reserva de divisas de guerra, resultantes de acordos internacionais, foi investida na importação de bens de consumo, estagnando a ainda incipiente indústria brasileira. Embora no país mal se praticasse o projeto de produtos, a estética do styling e da Bauhaus aqui chegaram via produtos norte-americanos. Apenas após o conturbado período de 1954 a 1956, dos curtos governos de Café Filho, Carlos Luz e Nereu Ramos, Juscelino Kubtschek assumiu a presidência e comandou a primeira fase significativa da Industrialização Brasileira, passando a ser o estabelecimento de uma sociedade capitalista de consumo um “projeto de Estado" (NIEMEYER, 2007, p.53), alinhando o Brasil ao desejo de atingir o bemestar social norte-americano.

$\mathrm{O}$ sucesso das premissas modernistas, na primeira metade do século $\mathrm{XX}$, ajudou a estabelecer no Brasil o anseio por este tipo de sociedade. Os produtos industrializados passaram a ter importância cultural e foram incorporados ao desejo do cidadão comum. A estética do modernismo, baseada na racionalidade, poderia ser interpretada por alguns como sendo o caminho para uma sociedade mais igualitária, enquanto por outros era vista como uma 
"expressão do nacional-desenvolvimentismo", o que permitiu uma homogeneização da estética modernista para ideologias políticas opostas, de modo que o comunista Oscar Niemeyer trabalhasse lado-a-lado com o desenvolvimentista Juscelino Kubitschek (NIEMEYER, 2007, p.56). Entre as décadas de 1940 e 1960 o Brasil passa a se afirmar no projeto de Móveis, com nomes de arquitetos que vieram a se tornar designers de grande importância, inclusive no cenário internacional, como Geraldo de Barros, José Zanine Caldas, Lina Bo Bardi, Paulo Mendes da Rocha, Joaquim Tenreiro e Sérgio Rodrigues. Assim começava-se a determinar a importância do Brasil no cenário mundial nesta área no design de mobiliário, posição que ainda ocupa hoje.

A modernidade também foi a responsável pela chegada "oficial" do Design no Brasil. O Design já era visto por artistas e intelectuais brasileiros como fundamental para o desenvolvimento e o progresso, mas sua importância estratégica parece não ter sido levada a sério, como fora feito pelas principais economias globais. Cardoso (2011, p. 175) lembra que, em uma inciativa pioneira, Raymond Loewy abriu, em 1947, uma filial de seu escritório de Design no Brasil, em São Paulo, dirigida pelo arquiteto Californiano Charles Sampson Bosworth, que não teve êxito e acabou fechando no mesmo ano, o que de certa forma pode ilustrar a não valorização do design como atividade estratégica no Brasil.

A primeira tentativa de discutir o design de forma sistemática, no Brasil, ocorreu no Instituto de Arte Contemporânea (IAC) do MASP - Museu de arte de São Paulo (NEIMEYER, 2007; CARDOSO, 2011). O instituto é "Idealizado e coordenado pela arquiteta Lina Bo Bardi (1914-1992) e por Pietro Maria Bardi (1900-1999), diretor do Masp, é inaugurado em março de 1951 e encerra as atividades no fim de 1953" (INSTITUTO, 2018). Max Bill (um dos professores da escola de Ulm) teria, em visita ao Brasil, colaborado para a iniciativa quando esteve visitando o país na II Bienal de São Paulo. Entretanto sua curta duração não permitiu a sistematização do ensino no país. Outra inciativa foi a escola do MAM (Museu de Arte Moderna), que também não foi viabilizada, mas cuja experiência serviu de base para a fundação da Escola Superior de Desenho Industrial - Esdi (CARDOSO, 2011 e ESCOLA, 2018), que inicia suas atividades em 1963, no Rio de Janeiro, apoiada pelo projeto desenvolvimentista do então governador da Guanabara, Carlos Lacerda. Nos anos de 1970, Cara (2010, p. 78) aponta que se incrementa o debate sobre o design como necessário ao desenvolvimento tecnológico do país. Em 1975, a Esdi foi incorporada como uma das unidades da Universidade Estadual do Rio de Janeiro - UERJ. Sua fundação tem currículo fortemente influenciado pela Escola de Ulm, o que ajudou na fundação de um Design Brasileiro inspirado no germânico. Em 1962, uma especialização em Desenho Industrial (ou sequência) do curso de Arquitetura foi instalada na 
Universidade de São Paulo - USP (CARDOSO, 2011). A influência da Esdi é reconhecida na fundação das escolas de Design nas décadas seguintes. Niemeyer (2007, p. 122) critica o currículo inspirado em Ulm, pois este não teria levado em consideração a realidade do setor produtivo nacional, o que causou um distanciamento entre a indústria e a academia, assumindo um “caráter dogmático" acerca do Design, não permitindo aos alunos uma "visão crítica".

A partir de 1964, o projeto desenvolvimentista muda de mãos e vai para o governo militar, mas o modernismo continua a ser visto com bons olhos para a "ordem e progresso". Neste período, o desenho industrial (moderno, funcional e racional) passa a fazer parte não só de Cursos Superiores, mas também do ensino técnico durante o militarismo, nas escolas técnicas federais - ETFs e centros federais de educação tecnológica - CEFETs. Assim, percebemos que o design no Brasil é instalado a partir do desenvolvimentismo, amparado por uma estética modernista tardia, embora o mundo já tivesse iniciado sua guinada para a pós-modernidade. Lucy Niemeyer (2007) nos alerta que estética modernista é antagônica à estética barroca de nossas raízes coloniais, mas a insistência no ensino embasado no modernismo refuta do design ideias que se contrapusessem aos ideais modernistas de sociedade, o que afastou, ainda mais, o design acadêmico aqui produzido da realidade e do gosto tradicional da sociedade brasileira, fator que pode ter contribuído para o desdém com a atividade que o designer enfrentou no Brasil, com reflexos até hoje.

No resto do mundo, o ensino do Design seguia a corrente alemã, mas também duas outras frentes modernistas relevantes, uma norte-americana, na qual se intensifica a interação entre design e pesquisa para o desenvolvimento de projetos, e onde também há uma maior liberdade formal (por influência do styling) e outra britânica, principalmente devido ao Royal College of Art, onde, a partir de 1948, há uma orientação voltada para a produção industrial, na qual o caráter técnico não permitiu abrir mão da arte e investiu na pesquisa avançada que ligou o design às descobertas da engenharia (CARDOSO, 2011), trazendo uma pluralidade não encontrada nas outras vertentes, intensificando a relação entre design e tecnologia.

\section{Transformação Cultural}

O movimento moderno pode ser, com certa justiça, acusado de elitista, mesmo que num primeiro momento se alinhasse com pensamento reformador social-democrata dos anos 1920 (BONSIEPE, 2012, p.104). Quem, na verdade, tem acesso aos ícones do design moderno? A maioria dos produtos custa caro e não é de acesso democrático. E, não apenas por isso, o modernismo estava, de certa forma, com os dias contados. O racionalismo que imperou no início 
do século XX acabou resultando em uma sociedade injusta e na degradação ambiental. Um dos símbolos do final da modernidade pode ser a explosão atômica em Hiroshima, no ano de 1945 (SANTOS, J. F. 2012): a bomba não só dizimou a cidade e sua população, mas sua radiação puniria as gerações seguintes pelo fracasso de seus antepassados na guerra e, ainda assim, as soluções para a morte em massa durante a segunda guerra eram tão extraordinárias, que talvez as explosões atômicas tenham poupado vidas ao fazer com que os inimigos dos aliados apresentassem sua rendição (BLAINEY, 2007). Aliado às mudanças que o mundo enfrentaria está o processo de globalização, alavancado pelo avanço das telecomunicações. A ciência conseguiu colocar o homem no espaço, descobriu o DNA e inventou o chip, que permitiu maior liberdade formal aos designers, uma vez que a eletrônica passou a não mais depender das válvulas e do espaço que elas ocupavam. O avanço tecnológico permitiu uma estética que não mais estivesse presa aos componentes do produto; a evolução da tecnologia resulta no High Tech, uma corrente de projeto que, tanto na arquitetura quanto no design, faz uso das novas tecnologias para propor soluções.

$\mathrm{Na}$ arte, o modernismo entra em crise. A Pop Art trouxe de volta o figurativo para as artes plásticas e tem reflexos no design. Cardoso (2011, p.199) chama a atenção para visões "antigeométricas, antifuncionalistas e anti-racionais", todas de oposição ao modernismo, cujos exemplos estão no design gráfico do Push Pin Studios, nos escritórios italianos Archizon e Superstudio, que pregavam o anti-design, termo cunhado em oposição a doutrinação modernista das escolas de design, nos anos de 1980. No Brasil tivemos a Tropicália, uma nova leva de ilustradores como Ziraldo e Jaguar e designers gráficos que abandonaram a estética modernista, buscando encontrar mais humor em suas peças. Em 1966, Robert Venturi lança a sua obra Complexidade e Contradição na Arquitetura, onde diz que "a doutrina do 'menos e mais' deplora a complexidade e justifica a exclusão para fins expressivos" (VENTURI, 1995, p. 4) em obra considerada como uma das precursoras do pós-modernismo na arquitetura.

Desde a década de 1960, o consumismo e a destruição da natureza passaram a ser criticada pelos hippies, ao ponto de seus pensamentos serem denominados de contracultura. A estética do modernismo foi, aos poucos, abandonada como item de desejo das novas gerações. Roupas passam a ser usadas mesmo gastas e rasgadas, como crítica ao consumismo. As cores vibrantes ressurgem e o conservadorismo é contestado, com movimentos étnicos e feministas, além de um desejo de liberdade de escolha que fugisse aos padrões impostos pela sociedade industrial moderna. Blainey $(2009$, p. 250) ressalta que "os méritos inconfundíveis dos Estados 
Unidos se transformavam em defeitos”, nos indicando que a poluição ambiental e a Guerra do Vietnã impulsionaram o "movimento ecologista".

\section{Design Para o Desenvolvimento Sustentável.}

A partir da primeira conferência sobre o Meio Ambiente de Estocolmo, em 1972, (e da primeira crise do petróleo) a preocupação com um design menos destrutivo começou de maneira ainda tímida. O designer Victor Papanek publicou em 1971 o livro "Design for the real world" ("Design para o mundo real") e trouxe para o design soluções simples, ecológicas e de baixo custo. Papanek é apontado por Kazazian (2009) e Cardoso (2011) como um dos primeiros designers contemporâneos a se preocupar com a Ecologia e com a responsabilidade social. Heskett (1980) chamava a atenção para a influência exercida sobre Papanek pelo arquiteto e designer norte-americano Buckminster Fuller, "cujas ideias sobre o papel social do designer têm uma notável e rara abrangência" (HESKETT, 1980, p.180). Na mesma época, em 1972, o atualmente famoso arquiteto Frank Gehry lançou a série Easy Edges que era composta de 14 móveis de papelão ondulado, que exploravam "as características estruturais e estéticas do papelão" (SANTOS, A., 2006 e RIBEIRO, 2000), e que hoje podem ser referência em móveis feitos de material ecológico.

O movimento por um design 'mais ecológico’ avança nos anos 1970 e 1980, sendo que, a partir de 1990, mais especificamente a partir da Rio 92, algumas "vertentes estáveis" de projeto alinhados à ecologia já podiam ser identificadas: o 'design verde', o 'ecodesign' e o 'design sustentável' (DEWBERRY, 1996, p. 29). Após isso, literatura passou a ser publicada sobre aplicações de ferramentas de Design voltadas para o Desenvolvimento Sustentável. E surgiram pesquisadores aplicados em converter a profissão para a construção de soluções que trouxessem melhoria econômica, social e ambiental. A entrada do design para projetar em outros campos, como processos, sistemas e serviços, faz parte das abordagens ligadas à Sustentabilidade. O avanço da eletrônica aliada à cibernética, que resultou nos tablets, smartphones e smartwatchs, abrem novas portas para o design de aplicativos e de interface, à medida que avanços nos demais equipamentos e produtos surgem. Nesta linha tecnológica (ou da quarta Revolução Industrial, como alguns querem chamar) há um caminho otimista, que vê na tecnologia um futuro mais promissor para a humanidade, onde as descobertas científicas serão capazes de economizar nossos recursos ou mesmo, em um futuro não tão distante, buscá-los fora do planeta. Outro caminho otimista é o de que haja uma revolução cultural, provocada pela constatação do problema ambiental. Nesta revolução a sociedade de consumo seria substituída por uma nova, 
que demandasse menos recursos e fosse mais ligada à natureza. Essa visão, entretanto, parece ter um viés romântico exagerado e, mesmo que aconteça, não parece ter força para atingir toda a humanidade. Na mesma perspectiva, pode-se pensar que o ponto de inflexão da curva da degradação ambiental tenha sido atingido, e que, a partir de agora, o atual estágio da evolução tecnológica e intelectual permita a humanidade encontrar soluções que passem a diminuir a degradação até o ponto de revertê-la; e que o design terá um papel crucial nesta empreitada. Os mais pessimistas podem argumentar que seja tarde demais, que a curva da degradação agora é irreversível e que o design, aliado histórico da industrialização voltada para a sociedade de consumo, possui grande culpa na escassez de recursos.

\section{O Futuro Do Design}

A história do design nos trouxe a um ponto em que o futuro da profissão está posto em dúvida. Neste novo contexto, o papel do design aumenta ou diminui de importância? Ou será que nunca realmente teve importância e apenas surfou na onda do desenvolvimento da sociedade industrializada?

Durante a modernidade, o design ocupou aos poucos um espaço de destaque dentro da indústria, criando produtos que mantiveram a engrenagem da sociedade de consumo em movimento e ajudando a divulgá-los, através da propaganda e do ensino. Nas corporações, dentro da divisão industrial do trabalho, o design é uma das chamadas atividades de "pesquisa e desenvolvimento". Entretanto o "progresso técnico e a excelência do Design não podem ser mais vistos como incondicionalmente benéficos" (HESKETT, 1980, p.207). No princípio da modernidade imperava um pensamento crítico, mas esse pensamento esvazia-se ao passo que se constrói um modelo hegemônico e dogmático, válido em um primeiro momento para aplicação diferente para os países industrializados e para os em processo de industrialização, depois para o primeiro mundo e para o terceiro mundo e, por último, para os desenvolvidos e em desenvolvimento (ou centrais e periféricos). Pedro Luiz Pereira de Sousa, professor da ESDI e historiador do Design, afirma que

[...] esse esvaziamento se configura na construção de modelos que integrem arte, design e arquitetura, nos circuitos de produção e consumo da sociedade industrial [...] (e que) a arquitetura e o design pós-modernos podem representar um novo elemento de ruptura e, contraditoriamente, enquadrar-se num processo de crítica (SOUZA, 2008, p. 108-110).

O designer, inserido neste processo, vem criticando sua própria atuação. Um ponto fundamental talvez seja a ambiguidade de sua inserção no sistema projeto-produto, com relação 
à posição hierárquica do profissional na cadeia produtiva. Niemeyer (2007, p. 125) aponta que o designer ocupa, na cadeia produtiva, ora posição estratégica, intelectual (junto ao comando) e ora como parte das estruturas subordinadas (junto aos trabalhadores), a depender do ideal industrial que esteja submetido. A adoção de uma postura crítica pode depender deste enquadramento dentro do sistema produtivo, mas parece depender com mais importância da atividade acadêmica, onde, superadas as questões de metodologia de projeto, parece concentrar-se o pensamento crítico acerca do papel do design. Na mesma linha, Dewberry (1996, p.229) atentava para a relação entre a ética da Sustentabilidade e a posição ocupada pelo designer:

O designer, como indivíduo ou dentro de uma equipe de design, tem influência no resultado final de um projeto de design: o produto projetado. No entanto, o nível dessa influência depende de vários outros critérios, a saber: a prioridade dada ao design dentro do contexto do sistema de negócios; a integridade e consciência do designer individual: a relação entre o designer e outros elementos no processo de design e desenvolvimento; as últimas prioridades do negócio em que o designer opera. Então, em muitos aspectos, as barreiras para alcançar uma ética de design mais sustentável são aquelas impostas pelos sistemas empresariais, sociais e culturais. ${ }^{9}$

Outra questão importante para o posicionamento crítico do designer, é também o seu posicionamento geográfico. Gui Bonsiepe, um dos mais renomados estudiosos do Design LatinoAmericano, aponta que, dentro das políticas econômicas recentes na América Latina, "registra-se a implementação de duas opções diametralmente opostas", uma a favor da desindustrialização em prol do setor de serviços e outra de industrialização, preferencialmente com participação do capital nacional. Para ele, os países centrais mantêm sua posição de liderança com a "inovação tecnológica" e este fator divide os países entre "produtores e consumidores de tecnologia" (BONSIEPE, 2012, p. 80-86). Assim, a postura do designer não depende somente de estar em um país central ou periférico, mas também de qual país está e do contexto político em que está inserido. Podemos trazer essa reflexão para o Brasil, onde certamente haverá diferenças significativas entre ser um designer na Região Sudeste ou na Região Norte. Isso ainda é somado à particularidade de que o design industrial, como atividade estratégica, nem se pode dizer que de fato chegou aos países periféricos.

A inviabilidade ecológica do sistema baseado no individualismo está em crise, pois o acesso aos produtos de consumo por toda a população global demandaria por recursos que o planeta não seria capaz de repor. Bonsiepe (2012, p. 122) relaciona o chamado "design autoral" com os problemas resultantes da obsolescência programada, dizendo que:

\footnotetext{
${ }^{9}$ Tradução nossa.
} 
A obsolescência programada com o design correspondente e os produtos de baixa qualidade cumprem o desígnio de manter em circulação permanente as mercadorias. Sabe-se que é difícil corrigir esse processo, mesmo diante de muitos efeitos colaterais negativos. $\mathrm{O}$ debate sobre as alterações climáticas provocadas por ações humanas fornece um exemplo das enormes resistências para uma mudança de paradigma. Em vez de fomentar o consumo individualista, seria mais recomendável pensar em soluções comunitárias. Como consequência desta ênfase no consumo individualista surge o design de autor.

Apesar de constatados seus malefícios, esse processo é difícil de ser combatido. Aqui temos não apenas o individualismo do consumidor, mas também a busca por protagonismo do próprio designer enquanto indivíduo. Um posicionamento político do designer é cada vez mais inevitável, para se levar em conta a questão ambiental. Entretanto, os limites do design (e dos designers) não o mostram como o ator mais relevante para as mudanças nos sistemas sociais historicamente instalados, principalmente no contexto dos países periféricos, relegando a sobrevivência do designer à posição que tradicionalmente ocupou na história, mas que na periferia global ainda vem sendo ocupada à duras penas.

\section{Considerações Finais}

O design pode ser relacionado, em sua história, à degradação ambiental devido a sua ligação, e interferência crescente, nos processos produtivos e também à sua transformação em elemento da cultura, que em parte ajudou a promover o desejo pelo consumo. Contribuiu para a formação da Sociedade de Consumo a partir de dois fatores fundamentais: a ligação do design com a obsolescência programada, que chega ao seu auge em meados do século XX, e a adoção da estética modernista, apregoada como sinônimo de bom gosto. Na última década do século XX, o Design alinha-se com a crítica às mazelas da modernidade, que levou à conceituação da Sustentabilidade.

Em uma perspectiva mais otimista, pode-se pensar que o ponto de inflexão da curva da degradação ambiental tenha sido atingido, e que, a partir de agora, o atual estágio da evolução tecnológica e intelectual permita à humanidade encontrar soluções que passem a diminuir a degradação até o ponto de revertê-la - e que o design terá um papel crucial nesta empreitada. Os mais pessimistas podem argumentar que é tarde demais, que a curva da degradação agora é irreversível e que o design, aliado à industrialização, possui grande culpa nisso e não adianta agora tentar remediar a situação. Os caminhos possíveis para um design voltado para o desenvolvimento sustentável vêm sendo estudados por designers e acadêmicos realmente engajados com a questão. Entretanto, um posicionamento político, que normalmente é visto com maus olhos pelos que se dedicam às questões técnicas dentro da profissão de designer, é 
necessário para exercer qualquer mudança. $O$ futuro da profissão parece estar atrelado às transformações fomentadas pelas Nações Unidas, que busca uma modificação da sociedade sem rupturas bruscas nas estruturas sociais, políticas e econômicas. O tempo dirá se esse caminho será exitoso.

Finalmente, três questões podem ser propostas para a continuidade dos estudos sobre a relação entre design e sustentabilidade: no contexto da Atualidade, o papel do design aumenta ou diminui de importância? O design estaria ou não ainda alinhado às demais artes, no que concerne à crítica à indústria moderna? Como o design se divide entre o pensamento liberal, o pensamento conservador e a sustentabilidade?

\section{Referências Bibliográficas}

BAUMGARTEN, M. Conhecimento e sustentabilidade: Políticas de ciência e tecnologia no Brasil contemporâneo. Porto Alegre: Ed. UFRGS; Ed. Sulina, 2008.

BAXTER, Mike. Projeto de Produto: guia prático para o design de novos produtos. 3 ed. São Paulo. Blucher, 2011 (1 ed. 1995).

BINZTOK, J. Principais vertentes (escolas) da (des) ordem ambiental. In: SANTOS, M. et al. Território, Territórios: ensaios sobre o ordenamento social. 1 ed. Niterói. PPGEO/UFF, 2002.

BLAINEY, G. Uma Breve História do Mundo. São Paulo: Fundamento, 2007.

BONSIEPE, Gui. Design, como prática de projeto. São Paulo: Blucher, 2012.

BÜRDEK, B. História, teoria e prática do design de produtos. São Paulo: Edgar Blücher, 2010.

CARA, Milene. Do desenho Industrial ao design no Brasil: uma bibliografia crítica para a disciplina. São Paulo: Blucher, 2010.

CARDOSO, Rafael. Uma introdução à História do Design. São Paulo: Blucher, 2011.

DEWBERRY, E. Ecodesign. Tese de Doutorado. The Open University. 1996. Disponível em https://oro.open.ac.uk/19845/1/pdf75.pdf . Acesso em 03/09/2017.

DORFLES, Gillo. O design industrial e sua estética. São Paulo: Presença/Martins Fontes, 1978.

DROSTE, M. Bauhaus - Bauhaus-Archiv. 5 ed. Berlin: Taschen. (1 ed. 1990) 1995.

EAGLETON, Terry. Capitalismo, modernismo e pós-modernismo. Crítica Marxista, São Paulo, Brasiliense, v.1, n.2, 1995, p.53-68.

EHLERS, E. O ideal da sustentabilidade. In: EHLERS, E. O que é agricultura sustentável. São Paulo: Brasiliense, 2008., p.55-84.

ESCOLA Superior de Desenho Industrial (Esdi). In: ENCICLOPÉDIA Itaú Cultural de Arte e

Cultura Brasileiras. São Paulo: Itaú Cultural, 2018. Disponível em: http://enciclopedia.itaucultural.org.br/instituicao280406/escola-superior-de-desenho-industrialesdi> . Acesso em: 03 de Dez. 2018. Verbete da Enciclopédia. ISBN: 978-85-7979-060-7

FLUSSER, Vilém. $O$ mundo codificado: por uma filosofia do design e da comunicação. São Paulo: Cosac Naify, 2007. 
FORTY, Adrian. Objetos de Desejo: design e Sociedade desde 1750. (Edição Original: Objects of Desire: Design and Society since 1750, London: Thames and Hudson 1986), São Paulo: Cosac Naify, 2007.

GIDDENS, Anthony. A política da mudança climática. São Paulo: UNESP, 2009.

GOMBRICH, Ernest. The story fo art. Londres: Phaidon Press, 1997.

HARVEY, David. Condição pós-moderna. Uma pesquisa sobre as origens da mudança cultural. 17. ed. (1. ed. 1989). São Paulo Loyola, 2008.

HESKETT, J. Desenho Industrial. 4a. ed. Rio de Janeiro: José Olympio, 2012 (Título original: Industrial Design.1a. ed. Thames and Hudson. Londres: 1980).

HOBSBAWN, E. J. Da Revolução Industrial Inglesa ao Imperialismo. Rio de Janeiro. Forense, 1979.

INSTITUTO de Arte Contemporânea (IAC). In: ENCICLOPÉDIA Itaú Cultural de Arte e Cultura Brasileiras. São Paulo: Itaú Cultural, 2018. Disponível em: http://enciclopedia.itaucultural.org.br/instituicao468881/instituto-de-arte-contemporanea-iac . Acesso em: 03 de Dez. 2018. Verbete da Enciclopédia. ISBN: 978-85-7979-060-7

KAZAZIAN, T. Haverá a idade das coisas leves: design e desenvolvimento sustentável. Edição Original: Il y aura l'àge des chose légères: design et dévoloppement durable, 2003. 2. ed. São Paulo: SENAC, 2009.

LYNTON, N. O mundo da Arte - Arte moderna - Enciclopédia das artes plásticas de todos os tempos. Rio de Janeiro: Encyclopaedia britannica do Brasil Publicações LTDA, 1978.

MACKENZIE, D. Green design. Design for the Environment, London: Laurence King Ltd. 1991. ISBN 1856690016-9781856690010

MANZINI, E; Cullars,, J. Prometheus of the Everyday: The Ecology of the Artificial and the Designer's Responsibility, Design Issues. Vol. IX No. 1. 1992

MANZINI, E.; Vezzoli, C. O desenvolvimento de Produtos Sustentáveis; os requisitos ambientais dos produtos industriais. São Paulo: USP, 2005.

MARX, Karl. O Capital. 1 ${ }^{\text {a }}$. ed 1897. Domínio Público - Governo do Brasil.. Disponível em: <www.dominiopublico.gov.br/download/texto/ma000086.pdf> Acesso em 30/09/2018

NIEMEYER, Lucy. Design no Brasil: origens e instalação. 4 ed (1 ed. 1997). Rio de Janeiro: $2 \mathrm{AB}, 2007$.

ONU - Organização das Nações Unidas. Meio Ambiente. 2017. Disponível em $<$ https://nacoesunidas.org/acao/meio-ambiente/>

OLIVEIRA, M. M dos S. Marcuse e Jameson: da cultura afirmativa ao Pós-modernismo. Revista Estudos e Pesquisas em Psicologia. V11N1. Rio de Janeiro: UERJ. 2011 Disponível em: $<$ http://www.revispsi.uerj.br/v11n1/artigos/html/v11n1a12.html\#: :text=Hard\%20Times\%20(18 54)\%2C\%20Charles,sobre\%20as\%20sociedades\%20capitalistas\%20contempor\%C3\%A2neas>

PAPANEK, Victor. Design for the real word. 2 ed. Londres: Thames e Hudson, 2016. (1 ${ }^{\text {a ed }}$ 1971).

RIBEIRO, A. Frank. O. Ghery. - Móveis em papelão ondulado e madeira laminada. Arcoweb, 2000. Disponível em: <http://www.arcoweb.com.br/projetodesign/design/frank-o-gerhy-moveisem-01-04-2000>. Acesso em 06/12/2018. 
SANTOS, A. et al. Design em Papelão Ondulado - Série: Design Sustentável Brasil Curitiba: UFPR - Núcleo de Design \& Sustentabilidade, ISBN 85-905660-2-1, 88 p. 2006.

SANTOS, J. F. $O$ que é pós-moderno. 1 ed. $28^{\text {a }}$ reeimpressão. Coleção primeiros passos. São Paulo: Brasiliense, 2012.

SANTOS, Milton. et al. Território. Territórios. 1 ed. Niterói. PPGEO/UFF, 2002.

SMITH, Adam. A riqueza das Nações. Investigação sobre sua natureza e suas causas. Traduzido por Luiz João Baraúna, de SMITH, Adam. An Inquiry into the Nature and Causes of the Wealth of Nations.Edited by Edwin Cannan. Chicago, The University of Chicago Press, 1976. (N. do E.), 1996. Edição Original: 1776.

SOUZA, Pedro Luiz Pereira. Notas para uma história do Design. 4 ed. Rio de Janeiro: 2AB, 2008

THE WILLIAN Morris Society. Disponível em: <https://williammorrissociety.org/> Acesso em $05 / 06 / 2020$

VEIGA, J. E. Sustentabilidade: a legitimação de um novo valor. São Paulo: Senac, 2010.

VENTURI, Robert. Complexidade e contradição em arquitetura. São Paulo: Martins fontes, 1995.

WDO - World Design Organization (WDO), 2015 - Definition of Industrial Design. Disponível em <http://wdo.org/about/definition/>. Acesso em 10/10/2018.

Recebido em 11/06/2020 - Aprovado em 20/08/2020. 